\title{
EDITORIAL
}

\section{Intravenous Heparin, Thrombolytics, and Medical Marketing}

\author{
ERIC J. TOPOL, M.D.* and ROBERT M. CALIFF, M.D.** \\ From the ${ }^{*}$ Division of Cardiology, Department of Internal Medicine, The University of Michigan Medical Center, Ann Arbor, \\ Michigan, and the **Division of Cardiology, Department of Medicine, Duke University, Durham, North Carolina
}

\section{Introduction}

Prior to 1988 , little had been written about the benefit to risk ratio of adding heparin anticoagulation to intravenous thrombolytic therapy for patients with evolving myocardial infarction, and heparin was considered to be a relatively trivial issue in the overall scheme of coronary thrombolysis. In the past 2 years, however, a considerable body of new data has been derived from intensive clinical research, including the largest myocardial reperfusion trial thus far completed ${ }^{1,2}$ and five smaller randomized, controlled angiographic studies. ${ }^{3-7}$ Collectively, a major controversy ${ }^{8}$ has developed without the requisite unequivocal data necessary for its resolution. In this article we will review the major findings of these studies and discuss a new trial that, in part, is intended to provide balance to the heparin controversy.

The Gruppo Italiano per lo Studio della Sopravvivenza nell' Infarto Miocardico (GISSI-2) trial with the International Study Group randomly assigned 20,891 patients with acute myocardial infarction to receive either tissue plasminogen activator (tPA) or streptokinase (SK). ${ }^{1,2}$ The trial had a $2 \times 2$ factorial design, such that

Address for reprints: Eric J. Topol, M.D., Division of Cardiology, B1-F245, University of Michigan Medical Center, 1500 E. Medical Center Drive, Ann Arbor, MI 48109-0022. Fax: (313) 936-7641.

Submitted for publication October 31, 1990; accepted for publication December 3, 1990. an additional random assignment was to give either heparin 12 hours after thrombolysis (dose of $12,500 \mathrm{U}$ twice daily) or no heparin. All patients received $325 \mathrm{mg}$ of aspirin daily. The study demonstrated no difference of mortality reduction for both thrombolytic agents (30-day mortality $8.9 \%$ for tPA, $8.5 \%$ for SK) and no overall benefit for heparin ( 30 day mortality for the heparin group was $8.5 \%$ compared with $8.9 \%$ no heparin). Secondary evaluation of the data demonstrates a tendency for benefit for subcutaneous heparin with SK $(5,186$ patients, mortality = $7.9 \%$ ) compared without heparin $(5,199$ patients, mortality $=9.2 \%$ ) but this was not the case for tPA (with heparin $[\mathrm{N}=5,167]$ mortality $=9.2 \%$; without heparin $[\mathrm{N}=5,197]$ mortality $=8.7 \%$ ).

Recently, Peto and Collins ${ }^{9}$ have pointed out that in GISSI-2 there was actually an $11 \%$ mortality reduction for subcutaneous heparin if only patients who died after 12 hours are analyzed ( $5.8 \%$ vs $5.2 \%$ mortality, $2 \mathrm{P}<0.05$ ). Although not prespecified, there is rationale for considering such an analysis since the heparin therapy did not begin until 12 hours. However, as mentioned, the predominant benefit, if any, of subcutaneous heparin, even after 12 hours, was among the SK treated patients. A smaller trial that did not include aspirin therapy also demonstrated a reduction of hospital mortality for subcutaneous heparin and SK compared to SK alone (433 patients, mortality was $4.6 \%$ vs $8.8 \%$, respectively). ${ }^{10}$

As far as intravenous heparin and SK, the data are relatively limited. For example, there has not been a randomized trial with angiography. How- 
ever, in the large scale International Studies of Infarct Survival (ISIS-2) trial, at the discretion of the physician investigators an adjunctive heparin regimen was frequently opted for with SK therapy. Although the assignment was not randomized, the 5-week mortality of patients treated with SK and aspirin $(\mathrm{N}=1,463)$ was $9.6 \%$ compared with $7.6 \%$ for patients also receiving subcutaneous heparin $(\mathrm{N}=1,805)$, and $6.4 \%$ for extensive therapy with the addition of intravenous hep$\operatorname{arin}(N=1,024)$. These favorable results for $S K$, aspirin, and intravenous heparin were not accompanied by significant increase in stroke or intracerebral hemorrhagic events. However, the bias of administering a more aggressive heparin regimen to a lower risk group of patients is a possible explanation. The overall profile of clinical outcomes for intravenous SK and heparin is, nonetheless, very positive given this rather large data set.

In a relatively short period of time concurrent to GISSI-2's completion, there have been five randomized angiographic trials of tPA with or without intravenous heparin ${ }^{3-7}$ as summarized in Table 1. The study designs differed in many important aspects, particularly the timing of the angiogram, the dose of aspirin, use of a placebo heparin, and the sample size. In Thrombolysis and Angioplasty in Myocardial Infarction-3 $\left(\right.$ TAMI-3) ${ }^{3}$ the angiogram at 90 minutes was the primary end point, and after that time the patients not initially receiving intravenous heparin were given this therapy. The dose of tPA was $1.25 \mathrm{mg} /$ $\mathrm{kg}$ with a maximum of $135 \mathrm{mg}$, which is higher than the currently recommended dose. Of note, the first angiogram at 90 minutes demonstrated a trend in favor of heparin for infarct vessel patency $(77 \%$ vs $71 \%)$, but this trend dissipated by the time of the "final" angiogram, which by convention in TAMI has been up to the fourth injection to standardize the potential for selective contrast injection facilitation of patency. Thus, the experimental findings that the fibrinolytic action of IPA is facilitated by intravenous heparin may be true,${ }^{11-13}$ particularly at a lower dose of tPA or with a larger population of patients assessed using the first angiogram as the primary end point.

The Heparin Aspirin Reperfusion Trial $(\text { HART })^{4}$ demonstrated a large $(30$ percentage point) difference in patency at 18 hours after randomization. In this trial, only $80 \mathrm{mg}$ of aspirin was given without an early dose on presentation. Furthermore, a higher proportion of patients with right coronary artery infarct vessels were randomly assigned to the nonheparin group. Bates et al. ${ }^{14}$ have shown that it is significantly more difficult to achieve thrombolysis with the right compared with left coronary artery. A smaller trial performed by Bleich and colleagues, ${ }^{5}$ also found a large (27 percentage point) difference in patency, at a mean of 40 rather than 18 hours after randomization, but no aspirin was given. The recently completed European Cooperative Study Group $^{6}$ enrolled the largest number of patients $(\mathrm{N}=644)$, assessed the patency later ( $2-5$ days, average of 80 hours), gave an immediate intravenous aspirin dose and a low alternate day oral regimen, and found only an 8 percentage point difference in patency. Of particular note, these

Table 1.

\begin{tabular}{|c|c|c|c|c|c|c|}
\hline \multirow[b]{2}{*}{ Study } & \multirow[b]{2}{*}{$\mathrm{N}$} & \multirow[b]{2}{*}{ Aspirin Dose* } & \multirow[b]{2}{*}{ Placebo } & \multirow[b]{2}{*}{ Time Assessed } & \multicolumn{2}{|c|}{ Patency (\%) } \\
\hline & & & & & Heparin & No Heparin \\
\hline TAMI- $^{3}$ & 170 & $325 \mathrm{mg}$ & No & $90 \mathrm{~min}$ & 79 & 79 \\
\hline HART $^{4}$ & 204 & $80 \mathrm{mg}$ & No & $18 \mathrm{hrs}$ & 82 & 52 \\
\hline Bleich et al. ${ }^{5}$ & 83 & None & No & $40 \mathrm{hrs}$ & 71 & 44 \\
\hline ECSG- $6^{6}$ & 644 & $\begin{array}{l}250 \mathrm{mg} \mathrm{IV}, \\
\text { then } \\
100 \mathrm{mg} \text { god }\end{array}$ & Yes & $80 \mathrm{hrs}$ & 83 & 75 \\
\hline $\mathrm{NHF}^{7 . * *}$ & 241 & $325 \mathrm{mg}$ & No & 7 days & 80 & 80 \\
\hline
\end{tabular}

ECSG = European Cooperative Study Group; HART = Heparin Aspirin Reperfusion Trial; NHF = National Heart Foundation; TAMI = Thrombolysis and Angioplasty in Myocardial Infarction; IV = intravenous; *administered orally daily unless otherwise specified; **andomization to heparin or no heparin was after 24 hours of intravenous heparin for all patients. 


\section{HEPARIN AND THROMBOLYTICS}

investigators found a direct relationship between the activated partial thromboplastin time and subsequent patency, further establishing the link between antithrombin effect and prevention of coronary thrombosis. The results are quite different in magnitude of heparin effect compared with the HART ${ }^{4}$ and Bleich et al. ${ }^{5}$ studies. It remains unclear whether the smaller, albeit statistically significant, difference in infarct vessel patency is due to angiographic assessment at a later time, the use of early, higher dose intravenous aspirin, or simply a more realistic assessment owing to a threefold increase in sample size.

The other randomized trial of tPA and intravenous heparin was performed by the National Heart Foundation of Australia. ${ }^{7}$ It differed substantially from the others because all patients initially received 24 hours of intravenous heparin. The patients assigned to discontinue heparin were instead given daily aspirin and dipyridamole and no difference in patency was found at predischarge evaluation.

The interpretation of these five trials is subject to considerable uncertainty and bias. On the one hand, we can definitely conclude that intravenous heparin helps to maintain infarct vessel patency with $\mathrm{PPA}$. The major question that remains, however, is to what extent and how does this differ from SK, which may similarly benefit from coadministration of intravenous heparin. An additional key concern is the comparative risk of bleeding complications for these regimens.

These uncertainties, further stimulated by a very aggressive marketing approach by the manufacturer of tPA, ${ }^{15}$ have led to a situation in which the results of a major trial have had little effect on the choice of thrombolytic agents in the United States. With an extraordinarily large sample size and adequate statistical power, the GISSI- 2 and International trial has documented tPA and SK equivalency. While the adjunctive heparin regimen deserves careful study, the findings of GISSI- 2 are unequivocal until proven otherwise. Given the encouraging new data for combination thrombolytic therapy (with heparin and aspirin), ${ }^{16-21}$ front loaded tPA regimens, ${ }^{22-24}$ and the frequent clinical practice of administering intravenous heparin with thrombolytics, we, in collaboration with many other clinical investigators in the United States and abroad have just initiated a 33,600 patient trial with the acronym of GUSTO (Global Utilization of Streptokinase and tPA for Occluded Coronary Arteries). The primary objective of this trial will be to evaluate the effects of rapid and sustained infarct vessel patency on survival.

\section{References}

1. Gruppo Italiano per lo Studio della Sopravvivenza nell' Infarto Miocardico. GISSI-2: A factorial randomized trial of alteplase versus streptokinase and heparin versus no heparin among 12,490 patients with acute myocardial infarction. Lancet 1990; 336:65-71.

2. The International tPA/SK Mortality Trial Study Group. In-hospital mortality and clinical course of 20,891 patients with suspected acute myocardial infarction randomized between tissue plasminogen activator or streptokinase with or without heparin. Lancet $1990 ; 336: 71$ 75 .

3. Topol EJ, George BS, Kereiakes DJ, et al. A randomized controlled trial of intravenous tissue plasminogen activator and early intravenous heparin in acute myocardial infarction. Circulation 1989; 79:281-286.

4. Hsia J, Hamilton WP, Kleiman N, et al. The heparinaspirin reperfusion trial (HART): A randomized trial of heparin versus aspirin adjunctive to tissue plasminogen activator-induced thrombolysis in acute myocardial infarction. N Engl J Med 1990; 323:1433-1437.

5. Bleich SD, Nichols T, Schumacher R, et al. The role of heparin following coronary thrombolysis with tissue plasminogen activator (t-PA). (abstract) Circulation 1989: 80:II-113.

6. De Bono DP on behalf of the European Cooperative Study Group. The need for anticoagulation with heparin after rt-PA, an angiographic study of 650 patients treated with rt-PA with or without intravenous heparin. Presented at the European Congress of Cardiology, September 20, 1990, Stockholm, Sweden.

7. National Heart Foundation of Australia Coronary Thrombolysis Group. A randomized comparison of oral aspirin/dipyridamole versus intravenous heparin after rtPA for acute myocardial infarction. (abstract) Circulation 1989; 80:II-114.

8. White HD. GISSI-2 and the heparin controversy. Lancet 1990; 336:297-298.

9. Collins R, Flather M, Peto R. GISSI-2; $10 \%$ reduction in mortality with heparin in acute myocardial infarction? Lancet 1990; 336:439-440.

10. The SCATI (Studio Sulla Calciparina Nell'Angina E Nella Thrombosi Ventricolare Nell-Infarto) Group. Randomised controlled trial of subcutaneous calcium-heparin in acute myocardial infarction. Lancet $1989 ; 2: 182$ 186.

11. Cercek B, Lew AS, Hod $\mathrm{H}$, et al. Enhancement of thrombolysis with tissue-type plasminogen activator by pretreatment with heparin. Circulation 1986; 74:583587.

12. Andrade-Gordon $\mathbf{P}$, Strickland $\mathbf{S}$. Interaction of heparin with plasminogen activators and plasminogen: Effects on the activation of plasminogen. Biochem 1986; 25:4033-4040. 
TOPOL, ET AL.

13. Agnelli G, Pascucci C, Cosmi B, et al. Failure of therapeutic doses of heparin to improve thrombolysis with tissue-type plasminogen activator in rabbits. Blood 1990; 76:2030-2036.

14. Bates ER, Califf RM, Stack RS, et al. Thrombolysis and Angioplasty in Myocardial Infarction (TAMI-1) Trial: Influence of infarct location on arterial patency, left ventricular function and mortality. J Am Coll Cardiol 1989;13:12-18.

15. Hamilton JO. Genentech: A textbook case of medical marketing. Business Week, August 13, 1990, pp. 96-97.

16. Topol EJ, Califf RM, George BS, et al. Coronary arterial thrombolysis with combined infusion of recombinant tissue-type plasminogen activator and urokinase in patients with acute myocardial infarction. Circulation 1988; 77:1100-1107.

17. Califf RM, Topol EJ, Harrelson L, et al. In-hospital clinical outcomes in the TAMI 5 study. (abstract) $\mathrm{J}$ Am Coll Cardiol 1990;15:76A.

18. The URALMI Collaborative Group. Combination of urokinase and alteplase in the treatment of myocardial infarction. Coronary Artery Dis 1991 (In Press).

19. Bonnet JL, Bory M, D'Houdain F, et al. Association of tissue plasminogen activator and streptokinase in acute myocardial infarction: Preliminary data. (abstract) Circulation 1989; 80:II-343.

20. Grines CL, Nissen SE, Booth DC, et al. A new thrombolytic regimen for acute myocardial infarction using combination half dose tissue-type plasminogen activator with full dose streptokinase: A pilot study. J Am Coll Cardiol 1989; 14:573-580.

21. Grines CL, Nissen SE, Booth DC, et al. A prospective, randomized trial comparing combination half dose tPA with streptokinase to full dose tPA in acute myocardial infarction: Preliminary report. (abstract) J Am Coll Cardiol 1990;15:4A.

22. Neuhaus KL, Feuerer W, Jeep-Tebbe S, et al. Improved thrombolysis with a modified dose regimen of recombinant tissue-type plasminogen activator. J Am Coll Cardiol $1989 ; 14: 1566-1569$.

23. Wall TC, Topol EJ, George BS, et al. The TAMI-7 trial of accelerated plasminogen activator dose regimens for coronary thrombolysis. (abstract) Circulation 1990; 82:III-538.

24. Braunwald E. Enhancing thrombolytic efficacy by means of "front-loaded" administration of tissue plasminogen activator. J Am Col Cardiol 1990; 14:15701571. 